\title{
I-TOE- THE NEW CONCEPTUAL FRAMEWORK THAT DECONSTRUCTING CONCEPT OF TRUST IN E-GOVERNMENT THAT AFFECTS USAGE OF E- GOVERNMENT
}

\author{
Ban Qasim Al nidawy ${ }^{*}$, Safia Sidek ${ }^{2}$, Samer Ali Al-shami ${ }^{3}$ \\ and Abdelrafe Elzamly ${ }^{4}$ \\ ${ }^{1,2,3}$ Institute of Technology Management and Entrepreneurship, Universiti \\ Teknikal Malaysia Melaka, Malaysia \\ ${ }^{4}$ Faculty of computer and information technology, Al-Aqsa University, Palestine \\ 1*ban_alnidawy@uoitc.edu.iq, ${ }^{2}$ safiahsidek@utem.edu.my, \\ ${ }^{3}$ samerali@utem.edu.my, ${ }^{4}$ Abd_elzamly@alaqsa.edu.ps
}

\begin{abstract}
The widespread usage of ICTs has led to the inevitable evolution of services offered by the government to upgrowth of e-government. The e-government success requires the usage of these electronic services by citizens. Several challenges have been identified that limit the usage of e-government. In this context, many researchers argued that trust is one of the multiple influential determiners of the usage of e-government among users. An investigation of trust relative to the egovernment usage among users is still lacking. The goal of this study is to propose a research work that provides a nuanced realization of the constructs of trust that impact the usage of e-government among users. For this purpose, the factors that contribute to trust will be analyzed using an integration of two theories namely the UTAUT2 and TOE, the integration of UTAUT2 and TOE is known as I-TOE. The integration of the two theories will offered a comprehensive understanding of factors of trust that impact the usage of e-government. Our study adopt a quantitative research method to examine the determinants (variables) that have an important impact on trust, which eventually result in the enhanced usage of egovernment. A random stratified sample was used in this pilot study, consisting of students studying abroad and employees working in Iraq, spatially in the Ministry of Higher Education and Scientific Research to test the instrument. The outcomes of this study will be used to ascertain the reliability of the questionnaire and the clarity of its items to develop a multidimensional trust that enhances the usage of egovernment amongst users.
\end{abstract}

Keywords - Usage of e-government, Trust of e-government, Trustworthiness, UTAUT2, I-TOE

\section{INTRODUCTION}

The fast evolution of ICT has witnessed the widespread usage of web-based technology in almost all sectors be it the private or public sectors. One of the prevalent usages of web-based technology is the e-government, in which every government in the world are adopting e-government as the means to disseminate information and perform

Received: April 30, 2019

Reviewed: July 24, 2019

Accepted: July 29, 2019

${ }^{*}$ Corresponding Author 
daily transactions with its stakeholders. Although e-government has become an essential platform of communication globally, many have complained of its restrictive usage, especially in the developing countries. There are multiple definitions of e-government commonly can agree that e-government is a tool of providing information and services by the government to users and stakeholders through the use of ICTs.

Although e-government has been used in most countries around the world, its usage in the developing countries is still lagging behind [1]. Although there is an increasing availability of multiple types of e-government services, there has been an increasing concerns as to why only a certain group of citizens use electronic services [2]. Many countries have made an effort to adopt e-government due the various advantages facilitated by it, but it has not received much acceptance from the users [3], [4]. An important issue that has been raised in relation to this are the lack of awareness among the community about e-government, as well the loss of trust in the internet and the government among citizens [5]. This paper posits that the critical element for any successful usage electronic services is trust. Thus trust is a significant variable in determining the usage of electronic services. Trust is also related to privacy as [6], [7] claimed that building user's trust in the services offered by e-government is the basic ingredient of privacy. Gaining trust on a particular technology also depends on who compiles the data and the importance to ensure the provision of data in terms of informed integrity and reliability [8]. In this case, trust is viewed a complex concept as it comprises multiple constructs. Hence, there is a need to investigate the elements of trust that has significant relationship to the usage of e-government. However, providing reliable, valid and protected data will enhance the user's trust in technology [8]. Trust has become a significant issue with respect to the usage of online information due to the emergence of an abundance of unreliable information. The user's reluctance to use or adopt electronic services is related to security, privacy and transparency issues. Here lies the importance of the trust factor as it increases the intentions and willing to usage e-government by users if the government strengthens trust [9].

Trust in government is a vital variable in electronic services because it generates a sense of equity in usage, access to information and trust in security and privacy of data [10]. The variable of trust is one of the most important variables that determine satisfaction and adoption in e-government, this is because the feeling of trust has an effect on behavior [11], [12], [13]. The trust factor becomes increasingly important when the information involves risk considering electronic risk is a barrier for most users [14]. There have been studies highlighting that the usage of e-government service relied on citizen's trust in governments as well as on the internet [11], [3], [9], [15]. These studies argued that citizens who trust that their government can supply high-quality services will also trust other methods of substitutional service provided by their government. then, if citizens trust the internet as a channel to address their needs, citizens eventually trust the online services offered by the government [16], [17]. A certain level of trust in governments is necessary for the e-government enabled participatory process. [18] proposed that finding appropriate solutions on the barriers of citizen's trust is possible to reach the required usage level of e-government services.

\section{LITERATURE REVIEW}

A systematic literature review involving 58 articles have been conducted by the researcher [19]. Three digital databases were used for the selection of the 58 articles and based on the analysis six categories were identified. The researcher identified six categories of studies related to trust and e-government. The six categories are I) technology, II) users, III) government, IV) intermediaries, V) mixed aspects and VI) review papers. In general, there are studies that focus on a particular aspect of trust, namely technology, users, government or intermediaries only. There are also studies that 
involve more than one aspect of trust which are classified as the mixed aspect. Additionally, one of the articles investigated four aspects [1]. There are studies that claimed various technical factors as important in adopting e-government. One of the studies focuses on building user trust through information accuracy, reliability, relevancy and easy to use systems [13], while studies conducted by [12], [20] examined the impact of quality factors like information, system and service to increase trust. Studies conducted by [8], [21]. Quality information and online services in relation to trust. These issues raise trust towards online public services. [22] Show that transparency and trust are important. In their study, they investigated how information quality and channel characteristics mediate and moderate the impact on the relations amongst appropriate factors and citizen intention using e-government. A study conducted by [23] focusing perceived usefulness as the factor that impact on "trust in e-government". [24] Investigated the impact of factors related to the technological aspects perceived by citizens, such as PEOU, PU and P\&SC on "trust in e-government".

The presence of a third party that has knowledge in the use of e-government gives the user trust, so trust in intermediaries is a vital factor affects the trust of the user through the Citizen Service Center. The intermediary role in the context of e-government and the importance it has to improve trust between user and government was investigated by [37], [39].

Also, mixed aspects between technology and user that impact "trust in e-government". Study focused on the quality factors and divided digital of the society to consider the impacts of the quality of services for e-government on trust in government [28]. In addition, a disposition to trust DTT, perceived ease of use PEOU as variables that influence on "trust in e-government" [29]. Other studies focused on three aspects, which are the technology, government and users that influence 'trust in e-government'. Such as trust in government, the quality dimensions of e-government like information, system and service, the multi-dimensional trust, such as institutional, interpersonal and dispositional trust for e-government continual use intention is also considered [30] [31]. Only one study that investigates a combination of technology, the quality dimensions of e-government like information, system and service, government trust (reputation and past experience) users (education, disposition to trust and internet experience) and risk (security and privacy, performance risk and time risk) that affect "trust in e-government" [1]. According to the literature review, the gap is that no study focused on the dimensions of "trust in e-government". The proposed study will deconstruct the concept of trust that contributes to investigating four dimensions that impact "trust in e-government" [19].

\section{THEORETICAL FRAMEWORK}

According to the literature review there are various theories and models are utilized to predict the approval or use of technology Most of the existing studies (14) do not rely on theory or model Figure 1 shows the theories/models that have been used by researchers in this field, such as Delone and Mclean's model, TAM model, "unified theory of acceptance and use of technology" (UTAUT) and mixed of model and theory. the UTAUT theory adopted by many of these studies, some of which adopted the theory with other theories or models to suit the need of the study [5], [32], [34]. 


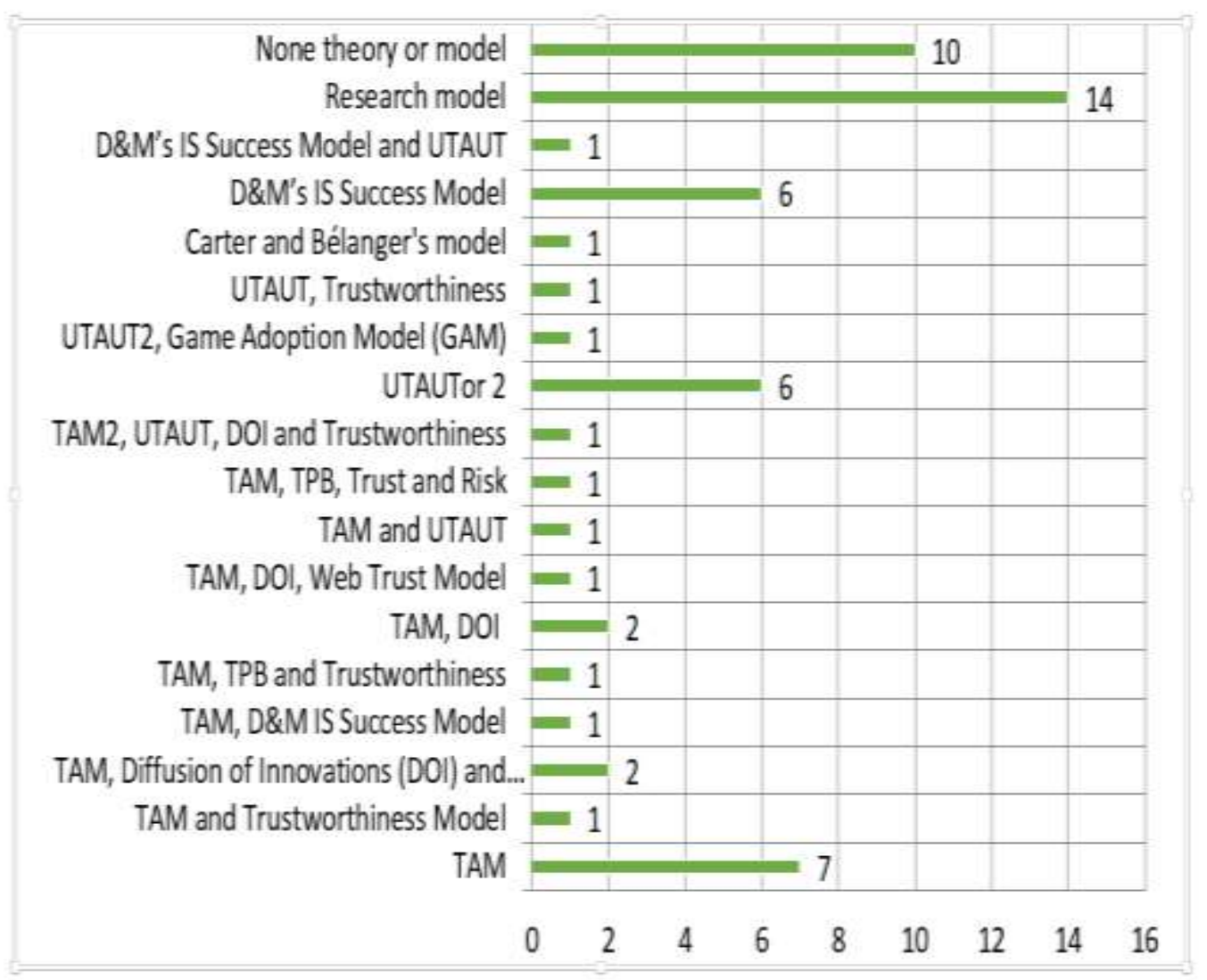

Fig. 1 Distribution by Theory/Model

The "Unified Theory of Acceptance and Use of Technology (UTAUT2)", which is an extension of UTAUT that resulted from a unification of eight prominent models of user interaction, namely, "Theory of Reasoned Action (TRA)", "Technology Acceptant Model (TAM)", "Diffusion of Innovation Theory (DOI)", "Theory of Planned Behavior (TPB)", "Motivational Model (MM)", "Combined TAM and TPB (C-TAM-TPB)", "Model of PC Utilization" and "the Social Cognitive Theory" [35]. Performance expectancy, effort expectancy, facilitating conditions, and social influences are proposed as four key constructs for explaining and predicting user acceptance of tested technology. [36] proposed UTAUT2, that combine hedonic motivation, price value, and habit constructs into UTAUT in the context of a consumer use, four key moderating factors, namely, age, gender, experience, and voluntariness of use, are also considered. We have chosen UTAUT2 with TOE theory for our study because UTAUT2 explained the individual aspect in an integrated manner better model among others, that UTAUT2 model resulted 74\% explained variance in use behavior [36], and according to the Table I which illustrates the strengths and weaknesses of models and theories. These two theories were chosen because they fully illustrate the aim of this study as well as that they have strong experimental support (the dimensions of "trust in e-government" that affect the use of egovernment). 
Table I. Comparison of Strengths and Weaknesses of Theories/Models

\begin{tabular}{|c|c|c|c|}
\hline Theory/model & $\begin{array}{l}\text { Root of } \\
\text { theory }\end{array}$ & Strengths & Weaknesses \\
\hline $\begin{array}{l}\text { Theory of } \\
\text { Reasoned } \\
\text { Action (TRA) }\end{array}$ & $\begin{array}{l}\text { this theory is } \\
\text { proposed by } \\
\text { Fishbein \& } \\
\text { Ajzen in } \\
1975\end{array}$ & $\begin{array}{l}\text { the key theory for } \\
\text { identifying consumer } \\
\text { behavioral changes. }\end{array}$ & $\begin{array}{l}\text { limitations in dealing } \\
\text { with certain aspects } \\
\text { of human behaviors } \\
\text { such as beliefs. }\end{array}$ \\
\hline $\begin{array}{l}\text { Theory of } \\
\text { Planned } \\
\text { Behavior } \\
\text { (TPB) }\end{array}$ & $\begin{array}{l}\text { an extension } \\
\text { of the TRA }\end{array}$ & $\begin{array}{l}\text { to understand the behavior } \\
\text { and beliefs of users about } \\
\text { technology is important to } \\
\text { explain their acceptance of } \\
\text { the use of this technology }\end{array}$ & $\begin{array}{l}\text { limited to control } \\
\text { beliefs and attitude. }\end{array}$ \\
\hline UTAUT & $\begin{array}{l}\text { blending } \\
\text { eight distinct } \\
\text { technology } \\
\text { acceptance } \\
\text { models based } \\
\text { on their } \\
\text { similarities. }\end{array}$ & $\begin{array}{l}\text { illustrate the intentions of } \\
\text { the user to use the IS and } \\
\text { usage behavior }\end{array}$ & $\begin{array}{l}\text { UTAUT capacity on } \\
\text { organizational } \\
\text { context. }\end{array}$ \\
\hline UTAUT2 & $\begin{array}{l}\text { extension of } \\
\text { UTAUT. } \\
\text { Venkatesh et } \\
\text { al. (2012) } \\
\text { proposed } \\
\text { UTAUT2. }\end{array}$ & $\begin{array}{l}\text { integrating price value, } \\
\text { hedonic motivation, and } \\
\text { habit constructs into } \\
\text { UTAUT in the context of a } \\
\text { consumer use, this addition } \\
\text { has led to the expansion of } \\
\text { UTAUT's capability from } \\
\text { the organizational context } \\
\text { to the consumer context. }\end{array}$ & \\
\hline TOE & $\begin{array}{l}\text { Tornatzky et } \\
\text { al. (1990) } \\
\text { proposed a } \\
\text { classic } \\
\text { framework } \\
\text { based on } \\
\text { Fred } \\
\text { Fiedler's } \\
\text { contingency } \\
\text { theory. }\end{array}$ & $\begin{array}{l}\text { addresses technological, } \\
\text { organizational and } \\
\text { environmental influence on } \\
\text { adoption of technology. }\end{array}$ & \\
\hline $\begin{array}{l}\text { Technology } \\
\text { Acceptance } \\
\text { Model (TAM) }\end{array}$ & $\begin{array}{l}\text { an } \\
\text { adjustment } \\
\text { of TRA and } \\
\text { TPB } \\
\end{array}$ & $\begin{array}{l}\text { address the use, acceptance, } \\
\text { and adoption concerns of } \\
\text { information systems }\end{array}$ & $\begin{array}{l}\text { only two major items } \\
\text { (PEOU) and (PU). }\end{array}$ \\
\hline TAM2 & $\begin{array}{l}\text { an extension } \\
\text { of the TAM }\end{array}$ & $\begin{array}{l}\text { focus on the determinants } \\
\text { of perceived usefulness and } \\
\text { expand it, in addition, } \\
\text { experience and } \\
\text { voluntariness were added as } \\
\text { moderators. }\end{array}$ & $\begin{array}{l}\text { ignored the attitude } \\
\text { toward using } \\
\text { technology. }\end{array}$ \\
\hline $\begin{array}{l}\text { Delone and } \\
\text { Mclean's } \\
\text { (D\&M) model }\end{array}$ & $\begin{array}{l}\text { presented in } \\
1992 \text { and } \\
\text { updated in }\end{array}$ & $\begin{array}{l}\text { measuring the complex } \\
\text { dependent variable net } \\
\text { benefits through user }\end{array}$ & $\begin{array}{l}\text { the model focuses on } \\
\text { the dimensions of } \\
\text { quality but avoids the }\end{array}$ \\
\hline
\end{tabular}




\begin{tabular}{|l|l|l|l|}
\hline Theory/model & \multicolumn{1}{|c|}{$\begin{array}{c}\text { Root of } \\
\text { theory }\end{array}$} & \multicolumn{1}{|c|}{ Strengths } & \multicolumn{1}{|c|}{ Weaknesses } \\
\hline & 2003 & $\begin{array}{l}\text { satisfaction focusing on the } \\
\text { dimension of quality. }\end{array}$ & $\begin{array}{l}\text { dimensions of other } \\
\text { aspects. }\end{array}$ \\
\hline $\begin{array}{l}\text { Diffusion Of } \\
\text { Innovation } \\
\text { (DOI) }\end{array}$ & $\begin{array}{l}\text { proposed by } \\
\text { Rogers in } \\
\text { (1983). }\end{array}$ & $\begin{array}{l}\text { explain users' adoption of } \\
\text { new technology }\end{array}$ & $\begin{array}{l}\text { limited to an } \\
\text { innovation relative } \\
\text { advantage; } \\
\text { compatibility; and } \\
\text { complexity. }\end{array}$ \\
\hline
\end{tabular}

\section{METHODOLOGY}

This study will investigate the relationship of trust that enhances the usage of egovernment among users. To achieve that we developed a conceptual framework after deep systematic literature review is framed based on two theories related to the usage of technology, namely the TOE and the UTAUT2, this framework is known as I-TOE that takes into consideration the aspects of individual, technological, organization and environment. It is expected that the inclusion of these aspects provides a holistic perspective for the determinants of trust. Considering quantitative research is designed to deal with large and complex data suitable for theoretical testing at an acceptable level of validity [38], this study will adopt a quantitative research method. The quantitative approach allows us to determine the significant determinants of trust that enhances the "usage of e-government". In this study, we used the questionnaire the most appropriate way to enable accurate data collection of the opinions of the users. The reliability of the instrument was tested through a pilot study. A Cronbach's Alpha was applied through a pilot study to check the reliability of the questionnaire.

\section{DEVELOPMENT THE MODEL}

\subsection{NEW CONCEPTUAL MODEL}

A conceptual model of this study has been adapted from UTAUT2, which has been enriched based on previous studies. In addition, this theory is the result of the unification of eight models and theories that have been used extensively in the adoption of technology. This conceptual model has also been integrated with TOE theory, which is named as I-TOE to produce a more comprehensive perspective on the understanding of trust and the use of e-government. The conceptual framework of this study consisting of four dimensions namely the individual, technological, organizational and environmental, is framed from the five aspects (technological, users, government, intermediary, risk) discussed in the literature review. The model will investigate the relationship of these dimensions with "trust in e-government" and thus the use of e-government. Our study goal to examine the construct of trust that influence the use of e-government among users. The focus of this study is to deconstruct the meaning of trust by investigating determinants that have significant influence on trust. The significant determinants of trust is believed to have the influence to enhance the 'usage of e-government' among users. This research adopted the integration of UTAUT2 and TOE as the lens to understand the significant influence of trust on the usage of e-government. It is argued that the integration of both theories offered a holistic understanding of the factors that influence trust as it involves the individual (UTAUT2), technological, organizational and environmental perspectives (TOE). In this study, the integration of UTAUT2 and TOE is known as I-TOE, indicating that I refers to individual, while T refers to technological, O refers to organizational and $\mathrm{E}$ refers to environmental. The integration of the two theories have been adopted by studies in other domains such as auditing [39] [40] [41]. Further, 
the inclusion of the four dimensions provides a holistic view of the use of e-government leading to a new viewpoint on the understanding of technology usage.

\subsection{DETERMINANTS OF TRUST}

To have a holistic perspectives of the determinants of trust, two theoretical perspectives have been integrated which are the UTAUT2 and the TOE theories. The UTAUT2 focuses on the individual or micro perspective that is the individual dimension that affect trust in using e-government, while the TOE theory focuses on the technological, organizational and environment dimensions of trust in using e-government. Additionally, other factors documented in the literature were also included in the four categories. The selections for determinants of trust have been made by filtered the studies according to the dependent variable so as to select the variable that influence the trust and thus to intention, adopt, use or accept the e-government. We found that there were 22 studies that examined the variables that affect the adoption, acceptance or intention of use. A total of 60 factors were identified that could potentially constitute user intention or adoption to use e-government. The following criteria used to determine the factors are as follows:

A. The factors were selected according to (UTAUT2, TOE) and needs of this study such as the factors that impact on trust (technological factors, users, government, intermediaries and risk) according to a gap of previous studies.

B. Grouped factors into four main categories according to similarity, such as the performance expectancy is grouped with perceived usefulness.

C. Similar or redundant factors are not included. In this case, factors that are viewed as the same category are formed as one factor.

D. The factors that have a greater frequency in the studies and have proved their importance and impact were selected such as perceived usefulness PU, ease of use PEOU, social influence, facilitating condition, trust of internet, trust of government, privacy and security, beliefs, intermediary and disposition to trust.

Prior studies reported that the perceived risk and service quality do not have high frequency. AL Athmay, Fantazy, and Kumar (2016) stressed that the quality of services has an influence on the adopted of e-government by users. The existence of risk, if any, will prevent the user from adopting these services and they will be less trust in these services [14]. By nature, people avoid risks and the use of internet services and computers pose multiple risks such as piracy, viruses, information theft, fraud, and time and money theft. This leads us to investigate risks as one of the important factors of trust in this context. According to our knowledge these two factors have a great impact on the users' trust, and they are the pillars of trust.

Drawn from UTAUT2, we selected the factors that match this theory such as our constructs of trust for the individual dimension. The four variables are "Performance Expectancy, Effort Expectancy, Social Influence, and Facilitating Condition". Although factors related to perceived ease of use and perceived usefulness has higher frequency, we identified effort expectancy instead of ease of use as well performance expectancy instead of perceived usefulness as variables for examining the causes of e-government adopted. The reason for this is due to the match in the definitions and measures of variables drawn from UTAUT [35]. As for the three factors (price value, hedonic motivation, habit) of extended the theory UTAUT, the studies did not address them as variable that impact trust in the context of e-government.

Supporting the legal framework is one of the hurdles challenging e-government. The absence of an enabling legal framework remains the main challenge facing e-government in Iraq [42]. The lack of a security culture affects the e-government adoption. Securing 
the e-government environment is through the building of a legal framework supported by all institutions dealing with electronic services or information technology in order to protect the consumer to avoid potential threats and ensure that institutions are accountable. This will affect their trust and acceptance of these electronic services. This represents an environmental factor in a TOE theory and it needs to be the focus of a study that investigates the ways to increase user trust and acceptance of e-services [13].

Top management support is one of the organization factors of TOE theory [39]. It is the decisions taken by top management that shape the direction of the institution towards adoption or non-adoption. It provides supportive climate, and this will affect the adoption of electronic services. On the contrary, refusal of top management to support these services will lead to the failure of adoption in all respects, so support the senior management is to draw the course of adoption of electronic services [10]. Therefore, we have to focus on top management and how interested and willing to adopt e-government and investigate the impact of management support on the trust factor in order to build comprehensive model.

The reputation of the institution in terms of fairness, equality and transparency in its dealings and the fulfillment of its obligations affect the trust of the user in this institution. Achieving justice, equality and transparency among all beneficiaries will lead to enhanced trust in this organization. On the contrary, institutions where nepotism and bribery policies are prevalent in their dealings, beneficiaries will be uncertain about the services offered to them [27]. If the organization does not tend to justice and equality in its policies, it will certainly hinder the adoption of electronic services and try to thwart them. On the contrary, if the organization follows the policy of justice and equality, the trust of individuals will increase and electronic services will be a priority. In all the previous studies, they have taken trust in the government in general only one study has adopted the reputation factor as one of the dimensions of government that affects trust in e-government but is still under study [1]. We will focus on reputation that reflects the trust of beneficiaries in the use of services provided to them.

The constructs of UTAUT2 model are: "performance expectancy, effort expectancy, social influence, facilitating conditions, hedonic motivation, price value, and habit" [36]. In our proposed framework, these factors with two other factors (disposition to trust and beliefs) refer to individual factors. Meanwhile, the technological factors include trust of internet, information quality, system quality, service quality and security \& privacy. The organizational factors consist of top management support, reputation and trust in government. Finally, the environmental factors include supporting legislation, trust of the intermediary and risk. This model will examine the effect of these aspects on "trust in egovernment" which leads users to usage e-government.

This study addresses the gaps in the past studies mentioned previously. For this purpose, our study examines the relationship of "trust in e-government" framed by four dimensions. The proposed model that illustrates these relationships is shown in Figure 2. 


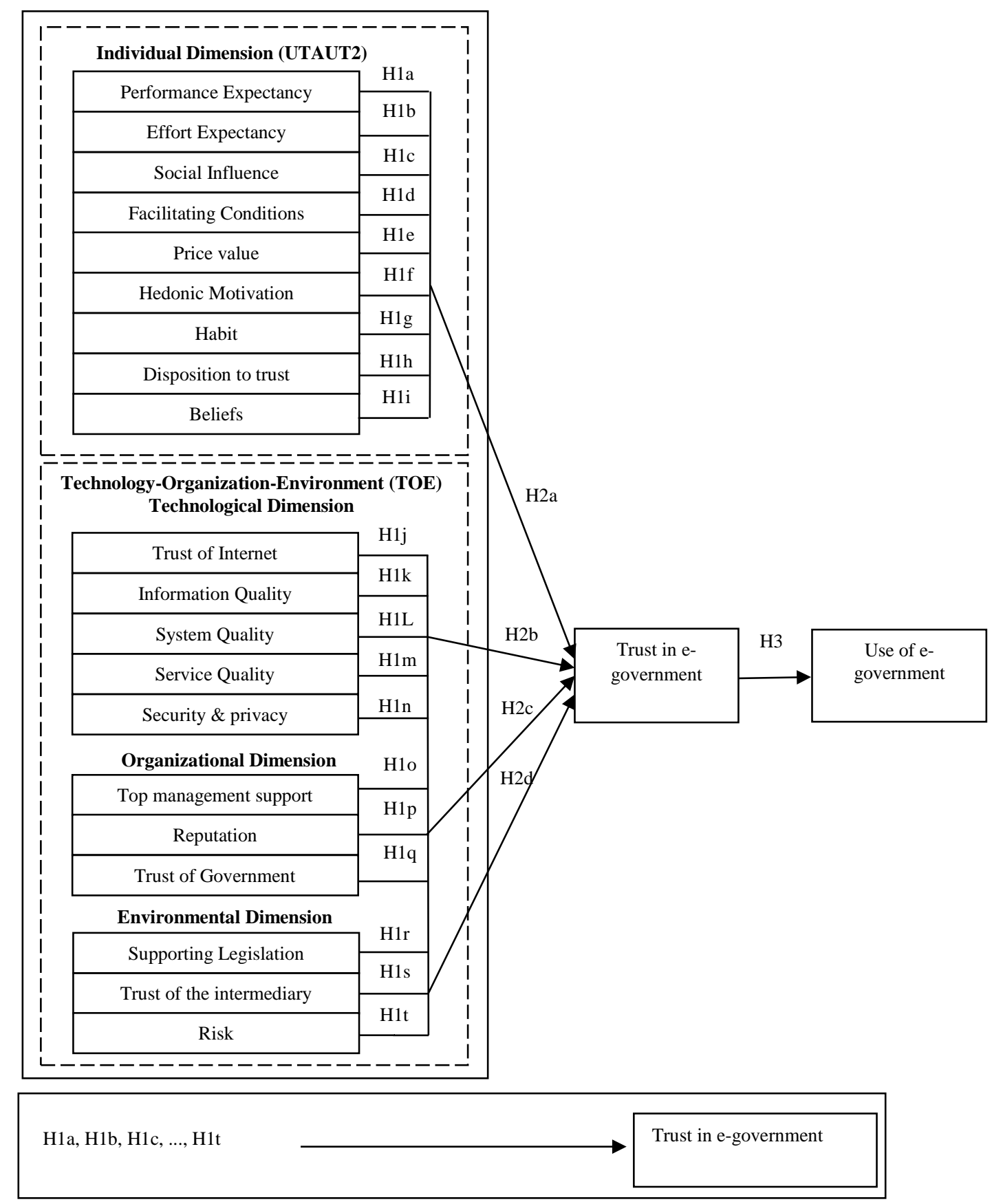

Fig. 2 Proposal framework

\subsection{RELATIONSHIP OF THE DETERMINANTS OF TRUST (I-TOE) AND TRUST IN E-GOVERNMENT}

This research focuses on investigating the construct of trust that has significant relationship to the usage of e-government. It advocates the need to deconstruct the meaning of trust by identifying the determinants that have significant relationship to trust. It is hypothesized that the determination of the determinants of trust that have significant relationship to the concept of trust has significant influence to enhance the usage of egovernment. 
To deconstruct the concept of trust, 20 determinants have been identified and these determinants were drawn from the literature (As described in the previous section). In this respect, 20 hypotheses will be tested to determine the significant determinants for the construction of trust. These hypotheses deal with the relationship of I-TOE "performance expectancy, effort expectancy, social influence, facilitating condition, price value, hedonic motivation, habit, disposition to trust, beliefs, trust of internet, information quality, system quality, service quality, security \& privacy, top management support, reputation, trust of government, supporting legislation, trust of the intermediary and risk" to "trust in e-government". The context of individuals includes a set of UTAUT2 structure, including other factors relating to individuals that may affect trust and the use of e-government. Although there are some studies that have adopted one or more of the factors mentioned above, the investigation of relationship between I-TOE and "trust in egovernment" addresses the gap in the existing literature. So far, this is the first time to check this relationship.

Empirical studies confirmed that "performance expectancy, facilitating conditions, social influence and trust of the internet" are crucial while user decides to usage the egovernment [11], [26]. Another study used an extended UTAUT2/GAM model to examine the factors that impact on behavioral intention and demonstrates that trustworthiness is the responsibility of the variance revealed by resistance to change where the relationship converts irrelevant with the addition of trust [43]. While another study indicates that trust is a mediator between security perception and behavior intention, it was the third important factor that influences behavior intention, performance expectancy and habit [44]. However, it is necessary to clarify that trust is not considered as a mediating variable, but rather as both independent and dependent variable as different stage of analysis in this study. As we see in the previous studies, the importance of factors of UTAUT2 on the intention of behavior and the e-government adoption, but has not achieved in the relationship with "trust in e-government". Our study also goal to analyze the four dimensions of the determinants of trust, namely the individual, technological, organizational and environmental dimensions that form the construct of trust. The purpose of analyzing these relationships is to determine the relationship of these dimensions in influencing trust. However, subsequent to the analysis of the determinants and the four dimensions of the determinants that form the concept of trust, the next part of the analysis is to analyse the relationship between the blackboxed trust and the usage of e-government. The blackboxed trust comprises the dimensions that have significant relationship with trust.

\subsection{INSTRUMENT PREPARATION AND DEVELOPMENT}

Towards examine the variable of trust that affect the usage of e-government in Iraq, an online survey will be conducted in the ministry of higher education of Iraq. According to the literature review the questionnaire involved 68 questions adopted from prior studies, with 6 questions were done to collect the demographic information and the two questions on the pattern of e-government usage by users and the constraints of e-government using. The questionnaire consists of two types of questions: 1) Multiple choices questions and 2) statements in which respondents are expected to respond based on a Likert scale. In our study, we used a five-point Likert scale of possible answers to scale each item of the response, differing from "1= strongly disagree to 5= strongly agree" [45].

Since the questionnaire will be distributed to the people of Iraq, the questionnaire was translated into the Arabic language which requires correct and accurate translation so that the results are accurate as well. We translated the English text of the questionnaire toward Arabic by three professional translators to validate the translation. The questionnaire was presented to ten academics in the field of e-government so as to ensure the validity of the contents, which corresponds to the concept that measures. 
The random stratified sampling technique will be used. The study population consists of students studying abroad and employees of the Iraqi Ministry of Higher Education and Scientific Research.

\section{PILOT STUDY}

The pilot study is necessary to maximize the instrument's validity and reliability for the study, the researcher investigates the validity and reliability of the study through Cronbach's Alpha to measure the internal consistency, to test the consistency between multiple measurements research variables. Cronbach's Alpha "is a popular analysis that is applied to estimate the internal consistency of a measuring scale" [46].

To test the reliability of building measures (items) to improve and finalize the questionnaire, a pilot study was conducted for 40 participants from the ministry of higher education in Iraq, the sample included 20 students abroad and 20 employees from the Iraqi Ministry of Higher Education and Scientific Research. In addition, it is used to see how well respondents understand the items. In order to rephrase the words and make it more understandable by the respondents.

\subsection{RELIABILITY ANALYSIS}

It is very important to examine the reliability of the questionnaire through the pilot study before conducting the study on the final sample representing the study population. The reliability of the questionnaire items shows the internal consistency of these items and relative to each other. Cronbach's Alpha is a popular analysis that is applied to estimate the internal consistency. A reliability coefficient must be of 70 or higher, this value that most social science studies rely on. [3]. The alpha coefficient for overall reliability of .969 for all items which indicates high internal consistency. The internal consistency of the items ranged from 0.397 for Beliefs to 0.940 for Trust of the intermediary as we see in Table II. The internal consistency of Facilitating Conditions is 0.695 , note that the consistency coefficient is close to the desired parameter, this means that the reliability of this variable is very close to reach 0.7 that only need a value of 0.005 , so it is likely that increasing the sample size may increase it.

Table III. Reliability Analysis for All Items

\begin{tabular}{|l|l|l|}
\hline \multicolumn{1}{|c|}{ Construct } & N of Items & Cronbach's Alpha \\
\hline Performance Expectancy & 3 & .896 \\
\hline Effort Expectancy & 3 & .837 \\
\hline Social Influence & 3 & .825 \\
\hline Facilitating Conditions & 3 & .695 \\
\hline Hedonic Motivation & 3 & .879 \\
\hline Price Value & 3 & .913 \\
\hline Habit & 3 & .886 \\
\hline Disposition to trust & 3 & .842 \\
\hline Beliefs & 3 & .397 \\
\hline Trust of Internet & 3 & .872 \\
\hline
\end{tabular}




\begin{tabular}{|l|l|l|}
\hline \multicolumn{1}{|c|}{ Construct } & N of Items & Cronbach's Alpha \\
\hline Information Quality & 3 & .925 \\
\hline System Quality & 3 & .838 \\
\hline Service Quality & 3 & .924 \\
\hline Security \& privacy & 3 & .789 \\
\hline Top management support & 3 & .916 \\
\hline Reputation & 3 & .920 \\
\hline Trust of Government & 3 & .912 \\
\hline Supporting Legislation & 3 & .919 \\
\hline Trust of the intermediary & 3 & .940 \\
\hline Risk & 3 & .871 \\
\hline Trust in e-government & 4 & .874 \\
\hline Use e-government & 4 & .928 \\
\hline All items & 68 & .969 \\
\hline
\end{tabular}

The internal consistency of beliefs is 0.397 , if we delete question 3 from the items of beliefs variable the internal consistency will increase from 0.397 to 0.798 for this variable, but we prefer to change the third question to (I believe my knowledge is sufficient to use egovernment) instead of deleting because the measure of this factor is prepared by the researcher, it is very necessary to reconsider the question and change it to obtain reliability.

\section{RESULT}

\subsection{DESCRIPTIVE ANALYSIS}

According to the output of the descriptive analysis of the questionnaire, the results were as shown in Table IV. $77.5 \%$ of the respondents were male and $22.5 \%$ female. The largest proportion of the age group is more than 24 to 44 years reaching $75 \%$. The lowest age group of less 24 years reaching $5 \%$. The percentage of respondents who use egovernment once a month was $40 \%$. Followed by those who do not use e-government $30 \%$, followed by those who use e-government multiple times during the month $25 \%$, either who use e-government every day was $5 \%$. The patterns of use of e-government, which were in the seek information reached $57 \%$. 35\% of the respondents chose to communicate with the respective institutions to inquire and conduct online transaction for each. In this question, the respondent can choose more than one choice. The trust factor was the highest in respondents' responses to the difficulties and constraints they faced in the use of e-government it was $67.5 \%$, followed by Weak internet service $50 \%$. Followed by lack of knowledge and privacy \& security $35 \%$ for each. 
Table V. Demographic of Respondents

\begin{tabular}{|l|c|c|}
\hline Demographics & Frequency & Percent \% \\
\hline Gender & 33 & 77.5 \\
Male & 9 & 22.5 \\
Female & 2 & 5 \\
\hline Age groups & 30 & 75 \\
Under 24 years & 8 & 20 \\
Between 24 - 44 years & 12 & \\
Above 44 years & 16 & 30 \\
\hline Frequent to use the e-government & 10 & 40 \\
Never & 2 & 25 \\
Once a month & 23 & 5 \\
Several time a month & 14 & 57.5 \\
Every day & 14 & 35 \\
\hline Purpose of using e-government & 0 & 35 \\
Seek information & & \\
Communicate with the respective institutions to & & \\
inquire & 27 & 67.5 \\
Conduct online transaction & 14 & 35 \\
Other & 20 & 50 \\
\hline Difficulties and limitations in using e-government & 14 & 35 \\
Trust & 0 & \\
lack of knowledge & & \\
Weak internet service & & \\
Privacy \& Security & & \\
Other & & \\
\hline
\end{tabular}

The descriptive analysis was conducted on the items of the questionnaire and showed moderate means with respect to 22 variables: Performance Expectancy (3.93), Effort Expectancy (3.96), Social Influence (3.64), facilitating Condition (3.84), hedonic motivation (3.48), price value (3.62), habit (3.25), disposition to trust (3.17), beliefs (3.88), trust of internet (3.47), information quality (3.47), system quality (3.32), service quality (3.25), security \& privacy (3.35), top management support (3.35), reputation (3.34), trust in government (3.16), supporting legislation (3.22), trust of the intermediary (2.92), risk (3.32), trust in e-government (3.55) and use e-government (3.15).

According to Khasawneh \& Tarawneh, (2016) "the mean for every measure specified based on the guidelines of social sciences: the mean $(1.0-2.33)$ : low agreeability, $(2.33-$ 3.66): medium agreeability, and (3.66 - 5): high agreeability". The results showed that the lowest mean of item use was "I am not concerned that the information I submit through the intermediaries (e-offices) could be misused" (2.77) and the highest item was "My Internet experience is sufficient to use e-government" (4.23).

\section{CONCLUSION AND FUTURE RESEARCH}

Our study investigates the factors of "trust in e-government" and its relationship to the use of e-government services. Most studies focus on factors of trust with many other factors that determine and affect the intention and usage of e-government. These studies tend to have limited perspectives in understanding the relationship between trust and the use of e-government. In this case, our study goal to deconstruct the notion of trust by taking a more holistic perspective on the meaning of trust by investigate the relationship of trust to the use of e-government. Therefore, the integration between UTAUT2 and TOE theory is the best way to deconstruct the factor of trust based on individual 
represented by UTAUT2 and Technology-Organization-Environment represented by TOE. We believe that the research model provides a comprehensive understanding of the variables of trust that effect the use of e-government.

A pilot study has been done to measure the reliability of the measuring questionnaire for all items. The study showed a high consistency of .969 for all items using Cronbach' Alpha to test the reliability. According to the results of the pilot study we found that it is desirable to use a scale greater than the 5-point Likert scale, as the 11-point scale will be more accurate. In addition, the size of the sample has an impact on the results. Therefore, the use of a larger sample and then confirm the validation of the instrument used to generalize the results and verify the model hypotheses to accept the conceptual model. This research is part of the $\mathrm{PhD}$ study and is still ongoing to reach results.

\section{LIMITATION}

One of the challenges faced by the researcher was that some variables did not have measuring tools and were prepared by the researcher where these variables were added to their importance because the previous studies mentioned them in general without measurement such as beliefs and reputation and support legislation.

\section{REFERENCES}

[1] L. Alzahrani, W. Al-Karaghouli, and V. Weerakkody, "Analysing the critical factors influencing trust in e-government adoption from citizens' perspective: A systematic review and a conceptual framework," Int. Bus. Rev., vol. 26, no. 1, pp. 164-175, Feb. 2017.

[2] T. Nam, "Determining the type of e-government use," Gov. Inf. Q., vol. 31, no. 2, pp. 211-220, 2014.

[3] M. Rehman, M. M. Kamal, and V. Esichaikul, "Adoption of e-Government Services in Pakistan: A Comparative Study Between Online and Offline Users,” Inf. Syst. Manag., vol. 33, no. 3, pp. 248-267, Jul. 2016.

[4] R. T. Khasawneh and M. M. Tarawneh, "Citizens' attitudes towards e-government presence on social networks (e-government 2.0): An empirical study," in 2016 7th International Conference on Information and Communication Systems, ICICS 2016, 2016, pp. 45-49.

[5] Al. A. A. AL Athmay, K. Fantazy, and V. Kumar, "E-government adoption and user's satisfaction: an empirical investigation,” EuroMed J. Bus., vol. 11, no. 1, pp. 57-83, May 2016.

[6] E. Abu-Shanab, "Antecedents of trust in e-government services: an empirical test in Jordan," Transform. Gov. People, Process Policy, vol. 8, no. 4, pp. 480-499, 2014.

[7] A. Alawneh, H. Al-Refai, and K. Batiha, "Measuring user satisfaction from e-Government services: Lessons from Jordan,” Gov. Inf. Q., vol. 30, no. 3, pp. 277-288, Jul. 2013.

[8] M. C. Roy, A. Chartier, J. Crête, and D. Poulin, "Factors influencing e-government use in non-urban areas," Electron. Commer. Res., vol. 15, no. 3, pp. 349-363, Sep. 2015.

[9] R. Fakhoury and B. Aubert, "Citizenship, trust, and behavioural intentions to use public e-services: The case of Lebanon,” Int. J. Inf. Manage., vol. 35, no. 3, pp. 346-351, 2015.

[10] L. Waller and A. Genius, "Barriers to transforming government in Jamaica Challenges to implementing initiatives to enhance the efficiency, effectiveness and service delivery of government through ICTs (eGovernment)," Transform. Gov. People, Process Policy, vol. 9, no. 4, pp. 480-497, Oct. 2015.

[11] M. Kurfal1, A. Arifoğlu, G. Tokdemir, and Y. Paçin, "Adoption of e-government services in Turkey," Comput. Human Behav., vol. 66, pp. 168-178, Jan. 2017.

[12] V. Weerakkody, Z. Irani, H. Lee, N. Hindi, and I. Osman, "Are U.K. Citizens Satisfied With EGovernment Services? Identifying and Testing Antecedents of Satisfaction," Inf. Syst. Manag., vol. 33, no. 4, pp. 331-343, Oct. 2016.

[13] E. Khanyako and G. Maiga, "An information security model for e- government services adoption in Uganda," in IST-Africa Conference and Exhibition (IST-Africa), 2013, 2013, pp. 1-11.

[14] D. B. Seo and M. Bernsen, "Comparing attitudes toward e-government of non-users versus users in a rural and urban municipality," Gov. Inf. Q., vol. 33, no. 2, pp. 270-282, 2016.

[15] H. J. Wang and J. Lo, "Determinants of citizens' intent to use government websites in Taiwan," Inf. Dev., vol. 29, no. 2, pp. 123-137, May 2013.

[16] J. V. Chen, R. J. M. Jubilado, E. P. S. Capistrano, and D. C. Yen, "Factors affecting online tax filing An application of the IS Success Model and trust theory," Comput. Human Behav., vol. 43, pp. 251262, Feb. 2015.

[17] D. B. Gracia and L. V. Casaló Ariño, "Rebuilding public trust in government administrations through egovernment actions," Rev. Española Investig. en Mark. ESIC, vol. 19, no. 1, pp. 1-11, 2015. 
[18] G. Rodrigues, J. Sarabdeen, and S. Balasubramanian, "Factors that Influence Consumer Adoption of Egovernment Services in the UAE: A UTAUT Model Perspective," J. Internet Commer., vol. 15, no. 1, pp. 18-39, Jan. 2016.

[19] B. Q. J. Al-nidawy, S. Sidek, and S. A. Al-shami, "Systematic review of critical factors and their dimensions influencing trust in e-government for usage or willing to use by citizens: Taxonomy, open challenges, motivation and recommendations," Opción, vol. 34, no. 85, pp. 2748-2794, 2018.

[20] O. Agbabiaka and R. Ugaddan, "The public value creation of eGovernment: A test of the respecified is success model," in Proceedings of the Annual Hawaii International Conference on System Sciences, 2016, vol. 2016-March, pp. 2923-2932.

[21] T. D. Susanto and M. Aljoza, "Individual Acceptance of e-Government Services in a Developing Country: Dimensions of Perceived Usefulness and Perceived Ease of Use and the Importance of Trust and Social Influence," Procedia Comput. Sci., vol. 72, pp. 622-629, 2015.

[22] V. Venkatesh, J. Y. L. Thong, F. K. Y. Chan, and P. J. H. Hu, "Managing citizens' uncertainty in egovernment services: The mediating and moderating roles of transparency and trust," Inf. Syst. Res., vol. 27, no. 1, pp. 87-111, Mar. 2016.

[23] P. Chatzoglou, D. Chatzoudes, and S. Symeonidis, "Factors affecting the intention to use e-Government services," in ieeexplore.iee.org, 2015, pp. 1489-1498.

[24] E. A. Abu-Shanab, "E-government familiarity influence on Jordanians' perceptions," Telemat. Informatics, vol. 34, no. 1, pp. 103-113, 2017.

[25] R. Sharma and R. Mishra, "Investigating the role of intermediaries in adoption of public access outlets for delivery of e-Government services in developing countries: An empirical study," Gov. Inf. Q., vol. 34, no. 4, pp. 658-679, 2017.

[26] V. Weerakkody, R. El-Haddadeh, F. Al-Sobhi, M. A. Shareef, and Y. K. Dwivedi, "Examining the influence of intermediaries in facilitating e-government adoption: An empirical investigation,” Int. J. Inf. Manage., vol. 33, no. 5, pp. 716-725, Oct. 2013.

[27] A. Voutinioti, "Determinants of User Adoption of e-Government Services in Greece and the Role of Citizen Service Centres," Procedia Technol., vol. 8, pp. 238-244, 2013.

[28] S. Myeong, Y. Kwon, and H. Seo, "Sustainable e-governance: The relationship among trust, digital divide, and E-government," Sustain., vol. 6, no. 9, pp. 6049-6069, Sep. 2014.

[29] Q. Xie, W. Song, X. Peng, and M. Shabbir, "Predictors for e-government adoption: integrating TAM, TPB, trust and perceived risk," Electron. Libr., vol. 35, no. 1, pp. 2-20, Feb. 2017.

[30] R. Nulhusna, P. I. Sandhyaduhita, A. N. Hidayanto, and K. Phusavat, "The relation of e-government quality on public trust and its impact on public participation," Transform. Gov. People, Process Policy, vol. 11, no. 3, pp. 393-418, Aug. 2017.

[31] D. Belanche, L. V. Casaló, C. Flavián, and J. Schepers, "Trust transfer in the continued usage of public e-services,” Inf. Manag., vol. 51, no. 6, pp. 627-640, 2014.

[32] M. Freire, N. Fortes, and J. Barbosa, "Decisive factors for the adoption of technology in E-government platforms," in Iberian Conference on Information Systems and Technologies, CISTI, 2014, pp. 1-6.

[33] F. Amagoh, "Determinants of e-government diffusion in Nigeria," Inf. Dev., vol. 32, no. 4, pp. 11371154, Sep. 2015.

[34] W. H. S. Alkhilani and H. Sulaiman, "Identification of factors influencing G2C services acceptance in developing countries," in Conference Proceedings - 6th International Conference on Information Technology and Multimedia at UNITEN: Cultivating Creativity and Enabling Technology Through the Internet of Things, ICIMU 2014, 2015, pp. 141-145.

[35] V. Venkatesh, M. G. Morris, G. B. Davis, and F. D. Davis, "User acceptance of information technology: Toward a unified view," MIS Quart., vol. 27, no. 3, pp. 425-478, 2003.

[36] V. Venkatesh, J. Y. L. Thong, and X. Xu, "Consumer Acceptance and Use of Information Technology: Extending the Unified Theory of Acceptance and Use of Technology," MIS Quarterly, vol. 36. Management Information Systems Research Center, University of Minnesota, pp. 157-178, 2012.

[37] L. G. Tornatzky, M. Fleischer, and A. K. Chakrabarti, "The processes of technological innovation. Issues in organization and management series," Lexingt. Books. Available http//www. Amaz. com/Processes-Technological-Innovation-Organization/Management/dp/0669203483. Accessed June, vol. 10, p. 2013, 1990.

[38] O. P. Atieno, "An analysis of the strengths and limitation of qualitative and quantitative research paradigms," Probl. Educ. 21st Century, vol. 13, no. 1, pp. 13-18, 2009.

[39] H. O. Awa, O. Ukoha, and S. R. Igwe, "Revisiting technology-organization-environment (T-O-E) theory for enriched applicability," Bottom Line, vol. 30, no. 1, pp. 2-22, May 2017.

[40] K. Rosli, P. H. P. Yeow, and E.-G. Siew, "Computer-assisted auditing tools acceptance using I-Toe: a new paradigm," Computer (Long. Beach. Calif)., vol. 7, pp. 15-2012, 2012.

[41] K. Rosli, P. Yeow, and E.-G. Siew, "Factors influencing audit technology acceptance by audit firms: A new I-TOE adoption framework,” J. Account. Audit. Res. Pract., vol. 2012, pp. 1-11, 2012.

[42] N. Qader and M. Q. Kheder, "Challenges and Factors Affecting the Implementation of e-Government in Iraq,” J. Univ. Hum. Dev., vol. 2, no. 3, pp. 476-481, Jan. 2016.

[43] M. Z. I. Lallmahomed, N. Lallmahomed, and G. M. Lallmahomed, "Factors influencing the adoption of e-Government services in Mauritius," Telemat. Informatics, vol. 34, no. 4, pp. 57-72, 2017. 
[44] N. Alharbi, M. Papadaki, and P. Dowland, "The impact of security and its antecedents in behaviour intention of using e-government services,” Behav. Inf. Technol., vol. 36, no. 6, pp. 620-636, Jun. 2017.

[45] J. Dawes, "Do data characteristics change according to the number of scale points used? An experiment using 5-point, 7-point and 10-point scales," Int. J. Mark. Res., vol. 50, no. 1, pp. 61-104, Jan. 2008.

[46] D. W. Straub, "Validating instruments in MIS research," MIS Q., pp. 147-169, 1989. 